\section{Conclusion}

Eighteen months experience with unqualified NAs in community work with the confused elderly has been a great success. We were able to recruit high calibre staff and in future it may be that more training and supervision will be called for. Training and supervision are the keys to successful utilisation of unqualified staff. This has required a change in working practice of our CPNs who traditionally are free of these duties and are more used to working independently.

Two aspects of our NAs' duties should be stressed. Firstly, they are part of a psychiatric team and are concerned not simply with physical tasks. They are expected to provide emotional and psychological support of a simple kind. Secondly, they belong to a multidisciplinary team and have ready access to a wide range of expertise. These two aspects of the NAs' role mark them out as quite different both from other non-psychiatric NHS colleagues and from local authority home care workers.

Our conclusion is that given the right kind of support and guidance unqualified staff can perform an essential role in the care of the elderly mentally ill. Given the growing shortage of trained nurses it would seem likely that this model of working will become more common in the future.

\section{Reference}

Pattie, A. H. \& Gilleard, C. J. (1979) Manual of the Clifton Assessment Procedures for the Elderly (CAPE). Sevenoaks: Hodder \& Stoughton.

\title{
The development of a community support service for the chronically mentally ill in an inner city health district
}

\author{
StePhen Colgan, Senior Registrar in Psychiatry; and Keith Bridges, Consultant \\ Psychiatrist, Department of Psychiatry, Rawnsley Building, Manchester Royal \\ Infirmary, Oxford Road, Manchester M13 9WL
}

Community support teams are an important component of services for the chronically mentally ill who do not need to remain in hospital. In the autumn of 1989 the Department of Psychiatry in Central Manchester established a small team with a remit to develop such a service. The team is made up of four nursing staff (a charge nurse, staff nurse, SEN and a nursing auxiliary) with additional support provided by two occupational therapists, a clinical psychologist, consultant psychiatrist and senior registrar in rehabilitation psychiatry. This paper will briefly describe some of the experiences and problems that the service has encountered so far and some of the solutions that have been explored.
The philosophy of the service is to help clients live in the community as independently as possible with a reasonable quality of life. Patients seen by the team are referred to as 'clients' as part of a process to demedicalise their lives. Each one is allocated a 'keyworker' who carries out an initial assessment of social needs and identifies the type of help and support that is required. If these can be provided by the service, goals are formulated in consultation with the client and targets agreed. This management plan is then reviewed on a regular basis at team meetings to which the client is invited to attend. Following the initial assessment, the key worker has responsibility for co-ordinating 
the team's effort but does not necessarily provide the majority of the input.

At the outset the team was asked to provide a service to 13 people with varying degrees of disability living in a variety of accommodation settings. Due to our initial anxiety we attempted to make the service available for as much of the day as possible with an 'on-call' night service. This soon proved to be overambitious as the core nursing team was too small to sustain such a workload. Although the occupational therapists were able to share some of the workload intended for the nursing staff this proved unsatisfactory and led to an urgent revision of our working week. After much discussion the team decided to reduce its service to normal working hours $(9$ a.m. to 5 p.m.) but still to include weekends. The nursing staff, however, retained the flexibility to work beyond these hours should the need arise. These changes have been an effective compromise and to date no client has needed to call upon the department's normal 'emergency services'. Avoidance of the 'revolving door' appears to have led to a marked increase in clients' self-esteem.

One of the more vulnerable clients did, however, require a brief admission. Joan, who suffers from chronic schizophrenia, went through a period of profound self-neglect associated with marked thought disorder despite regular input from the team. Over a short period she lost a great deal of weight and was clearly incapable of seeing to her own safety. Support staff increased the time spent with her, but due to her deteriorating mental state Joan was unable to respond in a coherent way and was finally admitted to hospital. At first the team felt demoralised, particularly as previous admissions to hospital had had a deleterious effect on the client's abilities to look after herself. However it was possible to turn this adversity into a positive experience by maintaining close liaison with the hospital team and preparing Joan's flat for her speedy return. As a consequence her stay was kept to three weeks which contrasted sharply with previous admissions of several months. The transition from community to hospital and back again occurred with few difficulties and Joan was able to regard her stay as a well earned rest.

The initial weeks found many team members dealing with basic practical issues, in particular in helping the clients and their accommodation look more 'presentable'. This had a detrimental effect on staff's relationships with clients and on team morale generally. Several members of the service started to question the value of their skills and professional training. Although the work being done was clearly important for the clients, in order for the team to continue, new ways of fulfilling their own needs would have to be found. On reviewing our progress we recognised what overwhelming needs clients presented with and by contrast how limited our resources were. Perhaps due to our hospital origins we had felt the onus was upon us to meet all of our clients' demands 'in house'.

To overcome this dilemma two major strategies were developed. The first was to identify all the main areas of need that an individual had and in collaboration with the client to prioritise them. A plan was formulated in which just a limited number of these needs were addressed and then only if the client wished to work at them. For example Pat, who suffered from chronic schizophrenia, had very poor self care skills. Since acquiring her own flat her independent existence had been precarious. If left to herself she would spend most of her money on cigarettes with little left for basics such as food and utilities. At first much of the team's time allocated to Pat was spent cajoling her into doing some household cleaning, cooking and learning how to budget her money. This strained relationships to such an extent that contact with Pat became increasingly fraught and destructive. Recognising these problems, we decided that most of our time with Pat should be spent doing mutually enjoyable tasks rather than focusing on difficulties she was reluctant to address. Problems such as personal hygiene were still considered but not made the major issue. As a consequence of this change in management the situation has improved. For example, the arrangement of regular hairdressing appointments, which she enjoyed, provided a vital boost to her self-esteem and encouraged a more natural pride in her appearance. While this approach has not been successful with all clients, its benefits so far appear to have outweighed the potential problems that were originally anticipated.

A second strategy to resolve our problems was a commitment to utilise other resources already established in the community. To help with this we assembled a list of all the organisations, both voluntary and statutory, existing in our district. A member of the team made contact and visited each one in order to assess their relevance to our clients. This process of identifying and establishing a register of other services in our community is continuing to be developed and fits in well with our role as 'service brokers'.

Since the service was launched six months ago several factors have become apparent. First, it seems important to have a flexible operational policy which can be modified in the light of experience. Second, chronically disabled people often develop and maintain many assets which enable them to live in the community and have a better quality of life than they could ever have in an instituition, even though their homes may not match up to institutional standards in terms of tidiness and hygiene. The team in turn has had to adopt more realistic expectations about what a person can and cannot achieve. This has been particularly important with regard to the most disabled clients, for whom the overall goal may merely 
be to prevent or slow down the rate of further deterioration in their clinical and social state.

Third, in order to help these people maintain their tenureship in the community, the team has had to provide continuous input. That is, although clients seemingly live in less dependent settings, they have in fact remained highly dependent on staff support. If this support is taken away all clients are likely to deteriorate in their ability to cope with the demands of the community and their quality of life will suffer. Inevitably, the intensive and ongoing support that these people require has limited the number of new referrals that the team can take on. Fourth, the community support team has had to use hospital based services on occasions when a client's clinical state has deteriorated to a point where it has not been possible to manage him or her in the community. Fifth, a number of people have benefited from and preferred to be in a 'group-living' situation rather than by themselves. We originally thought that the majority of clients would choose to live in their own flat, but four people now living in a shared house have gained a great deal of support from each other and have been able to capitalise on each other's skills. One resident of a group home, Sue, a middle-aged woman with chronic schizophrenia, took great pleasure in providing a Christmas dinner for her companions. This enabled them to have their first independent Christmas for many years and minimised the need for team input. Finally, many of the clients have turned out to have a very restricted social network with limited opportunities to spend their time on meaningful activities, either social, recreational or work-related. There still remains a great need for further 'sheltered' services to be developed.

Overall the team has not had any major difficulties working in dispersed community locations. We have enjoyed helping clients in their own homes and have welcomed the opportunity of working with other agencies involved in caring for chronic patients. For the future, however, there are a number of important issues the team will have to address if it is to continue and develop. First, the size of the team is too small not only to maintain the current service when staff are on leave or sick, but also if it is to take on more clients. Related to this is how the team should mesh with similar established agencies in the district such as the CPN service and a Social Services Network Team (created to care for similar clients after the closure of local authority hostels).

Second, while good team relationships have kept inter-disciplinary conflicts to a minimum there remain difficulties which need further exploration. These include, for example, the extent to which vocational roles should overlap; team leadership; and whether nursing staff should attend to basic care needs of clients as they do in hospitals, or whether they should supervise some other group of staff in this type of work?

Third, maintaining team morale and enthusiasm for working over a long time with severely disabled people-especially with those who have refractory problems and impaired insight-will be a major challenge to the team. While the service currently uses a variety of team-building exercises, such as meeting with other workers in rehabilitation to develop new ideas, the long term responsibility for dealing with 'burn out' will need to be shouldered by managers. This will be particularly important if resources remain inadequate to implement community care programmes and because of the predicted demographic changes in the target work force.

Lastly with regard to senior registrar training, the experience of being involved in the development of this service has been rewarding in several ways: from being directly involved with patients in domiciliary settings, from working with colleagues from a variety of professional backgrounds, and from the opportunity of gaining some insight into the political machinations and problems that managers have in securing resources for this group of patients. 